Tohoku J. Exp. Med., 2010, 220, 183-186

\title{
Benefits of Once-Daily Administration of Cyclosporine A for Children with Steroid-Dependent, Relapsing Nephrotic Syndrome
}

\author{
Koichi Suzuki, ${ }^{1}$ Eishin Oki, ${ }^{1}$ Kazushi Tsuruga, ${ }^{1}$ Tomomi Aizawa-Yashiro, ${ }^{1}$ \\ Etsuro Ito ${ }^{1}$ and Hiroshi Tanaka ${ }^{1}$ \\ ${ }^{1}$ Department of Pediatrics, Hirosaki University School of Medicine, Hirosaki, Japan
}

\begin{abstract}
Cyclosporine $A(C s A)$ is an effective steroid-sparing agent for patients with steroid-dependent, relapsing nephrotic syndrome (SDRNS). The efficacy and safety of single-daily dose administration (SDD protocol) of CsA in selected patients with SDRNS has been reported. However, the efficacy of initial CsA treatment for children with SDRNS using the SDD protocol remains to be elucidated. The SDD protocol might be associated with lower clinical toxicity, compared to the conventional twice-daily dose administration (TDD protocol). Here we evaluated the efficacy and safety of the SDD protocol versus the TDD protocol in patients with SDRNS. The data from 19 patients $(9.9 \pm 4.2$ years old) were retrospectively collected and analyzed. Ten patients treated according to the SDD protocol for a mean of 27 months (SDD group), while 9 patients treated with the TDD protocol for a mean of 35 months (TDD group) as an initial CsA treatment. Although the mean daily CsA dose was significantly lower in the SDD group $(1.5 \pm 0.4 \mathrm{mg} / \mathrm{kg} /$ day vs. $3.7 \pm$ $0.7 \mathrm{mg} / \mathrm{kg} /$ day, $P<0.01$ ), there were no differences between the two groups in the mean minimum dose of prednisolone required for maintenance of clinical remission nor in the calculated relapse rate. One patient in the TDD group developed biopsy-proven mild CsA nephrotoxicity, whereas no patient in the SDD group showed nephrotoxicity. Despite a small number of patients, this study may support that the SDD protocol is at least as effective as the conventional TDD protocol, and is more cost-effective for selected children with SDRNS.
\end{abstract}

Keywords: children; cyclosporine A; frequently relapsing nephrotic syndrome; single-daily dose administration; steroidsparing effect

Tohoku J. Exp. Med., 2010, 220 (3), 183-186. C 2010 Tohoku University Medical Press

Children with steroid-dependent, relapsing idiopathic nephrotic syndrome (SDRNS) have a favorable long-term outcome (The International Study of Kidney Disease in Children 1981). However, continuous moderate to highdose administration of predonisolone (PDN) to maintain clinical remission is often associated with serious adverse effects (Ruth et al. 2005). In this context, cyclosporine A (CsA) has been reported to be an effective steroid-sparing agent for patients with SDRNS, and has been commonly administered twice daily (TDD protocol) under trough blood level monitoring $\left(\mathrm{C}_{0}\right)$ (Hino et al. 1998; Inoue et al. 1999; Kano et al. 1999; El-Husseini et al. 2005).

The recently developed oral microemulsion of CsA is considered to overcome its potential malabsorption. Its efficacy and safety when administered once daily [singledaily dose (SDD) protocol] under peak or 2-hour post-dosing blood level monitoring $\left(\mathrm{C}_{2}\right)$ in patients with SDRNS has also been reported (Tanaka et al. 2004; Nakahata et al. 2005; Rasche et al. 2007; Takeda et al. 2007). However, there is no consensus as to whether the SDD protocol of
CsA is as effective as the TDD protocol in children with SDRNS. We, therefore, have retrospectively evaluated the efficacy and safety of the SDD versus the TDD protocol for CsA administration in children with SDRNS.

Methods
Patients
From January 1998 to September 2005, 31 children with
SDRNS were treated with CsA at the Department of Pediatrics,
Hirosaki University Hospital. Of them, patients who received CsA of
previous formula were excluded from this study. Thus, 19 consecu-
tive children aged $9.9 \pm 4.2$ years who received microemulsion for-
mula of CsA as an initial CsA treatment were retrospectively evaluat-
ed. The definition and criteria for the diagnosis of SDRNS, and for
the remission and relapse of this condition were the same as those
used in the International Study of Kidney Disease in Children (The
International Study of Kidney Disease in Children 1981). Renal biop-
sies were performed in 15 of the 19 patients before CsA treatment,
and all specimens presented minor glomerular abnormalities without
any evidence of immunecomplex depositions except for the podocyte
detachment in electron microscopic examination.

Received January 6, 2010; revision accepted for publication January 16, 2010. doi:10.1620/tjem.220.183

Correspondence: Hiroshi Tanaka, M.D., Ph.D., Department of Pediatrics, Hirosaki University School of Medicine, 5 Zaifu-cho, Hirosaki 036-8562, Japan.

e-mail: hirotana@cc.hirosaki-u.ac.jp 


\section{Treatment protocol}

SDD group: Between 2002 and 2005, 10 patients with SDRNS on their most recent relapse were administered escalating doses of PDN. Thereafter, they were treated with CsA according to the SDD protocol, with an initial daily dose of approximately $2.0 \mathrm{mg} / \mathrm{kg}$ preprandial. The dose was subsequently adjusted so that the whole blood level 2 hours after dosing $\left(\mathrm{C}_{2}\right)$ was in the range of $600-800 \mathrm{ng} / \mathrm{ml}$ (Nakahata et al. 2005). More than 6 months prior to the start of CsA treatment, a trial of cyclophosphamide (CPA) at the dose of 1.5-2.0 $\mathrm{mg} / \mathrm{kg} /$ day for 8-12 weeks had proved ineffective, in terms of steroidsparing effect and reduction in the frequency of relapses, in 3 of the 10 patients.

TDD group: Between 1998 and 2001, nine patients with SDRNS on their most recent relapse were treated with CsA according to the TDD protocol after the children had attained remission with PDN therapy. CsA was started at a dose between 2.0 and $4.0 \mathrm{mg} / \mathrm{kg} /$ day in 2 divided doses after meals, and subsequently adjusted so that the whole blood trough level $\left(\mathrm{C}_{0}\right)$ was maintained in the range of $50-100 \mathrm{ng} / \mathrm{ml}$. Treatment with CPA prior to the start of CsA therapy had proved ineffective in 8 of the 9 patients.

All the patients had a long history of SDRNS, and were on continuous PDN therapy, administered according to our treatment protocol for minimal-change nephrotic syndrome (Tanaka et al. 2004; Nakahata et al. 2005). After the start of CsA, the PDN dose was gradually tapered $(0.2 \mathrm{mg} / \mathrm{kg}$ on alternate days per 4 weeks $)$ down to the minimal dose required for maintenance of clinical remission, or discontinuation, based on the clinical status of each patient. Since all patients were refractory SDRNS, treatment duration with CsA was relatively long.

\section{Clinical observations}

The minimal PDN dose required for maintenance of clinical remission, the calculated relapse rate (times per year) and the GFR estimated using Schwartz' formula (Schwartz 1992) were determined at baseline, and at a mean of 30.6 months (range 13-68 months) after the start of CsA.

Post treatment renal biopsies were performed in 5 patients of the SDD group, after a mean of 20 months (range 9-36 months) from the start of CsA, and in the 9 patients of the TDD group, after a mean of 27 months (range 20-36 months) from the start of CsA.

\section{Statistical analysis}

Data are expressed as the mean \pm S.D., and were analyzed by Wilcoxon's $U$ test and Mann Whitney's $U$ test using Stat View Graphics (Abacus Concepts Inc., Berkeley, CA.) computer software. A $P$ value of less than 0.05 was considered statistically significant.

\section{Results}

The baseline clinical characteristics of the 19 patients are shown in Table 1. There were 7 boys and 3 girls, with a median age of 10.7 years (range 3.7-15.4 years) at entry in the SDD group, and 9 boys, with a median age of 9.6 years (range 5.1-14.8 years) at entry in the TDD group. All 15 pre-CsA treatment renal biopsy specimens presented minor glomerular abnormalities without tubulointerstitial lesions. Blood pressure and renal function were normal in all patients.

The daily CsA dose $(\mathrm{mg} / \mathrm{kg})$ and the $\mathrm{C}_{0}$ level of the drug $(\mathrm{ng} / \mathrm{ml})$ differed significantly between the two groups, being lower in Group A. Whereas, the $\mathrm{C}_{2}$ level of CsA was higher in the SDD group (Table 1). The calculated 0- to 4-hour area under the concentration time curve $\left(\mathrm{AUC}_{0-4}\right)$ of CsA in the SDD group patients were within the range between $1660 \mathrm{ng} \times$ hour $/ \mathrm{ml}$ and $2460 \mathrm{ng} \times$ hour $/ \mathrm{ml}$. Unfortunately, the $\mathrm{AUC}_{0-4}$ value of the drug in the TDD group patients was not examined.

After the start of CsA, the minimum dose of PDN required to maintain clinical remission was significantly lower at the post-treatment evaluation, compared to the respective value at baseline in both groups (Table 2). As a result, PDN could be withdrawn in 4 of $9(44.4 \%)$ patients in the SDD group, and 3 of 10 (30\%) patients in the TDD group during the CsA treatment period. After the discontinuation of CsA, none of the patients in either group showed a decrease in the estimated GFR. The calculated relapse rate (times per year) post CsA treatment was significantly lower in both groups than that during CsA treatment $(P<0.01$, respectively).

Although the mean follow-up period from CsA treat-

Table 1. Baseline characteristics of patients treated with CsA according to the SDD protocol (SDD group) or the TDD protocol (TDD group) .

\begin{tabular}{lcc}
\hline \multicolumn{1}{c}{ Variable } & SDD group $(n=10)$ & TDD group $(n=9)$ \\
\hline Age at onset (years) & $8.9 \pm 5.6(2.8-14.5)$ & $7.8 \pm 3.8(3.7-13.6)$ \\
Age at the start of CsA (years) & $10.7 \pm 5.0(3.7-15.4)$ & $9.6 \pm 3.8(5.1-14.8)$ \\
CsA dose $(\mathrm{mg} / \mathrm{kg}$ per day) & $1.5 \pm 0.4(0.9-2.1)$ & $3.3 \pm 0.7^{\mathrm{b}}(2.3-4.35)$ \\
$\mathrm{C}_{0}$ level $(\mathrm{ng} / \mathrm{mL})$ & $30.5 \pm 9.9(16.0-47.0)$ & $65.6 \pm 17.6^{\mathrm{b}}(37.0-88.5)$ \\
$\mathrm{C}_{2}$ level $(\mathrm{ng} / \mathrm{mL})$ & $829.0 \pm 172.9(570-1180)$ & $497.8 \pm 181.3^{\mathrm{c}}(315-734)$ \\
Calculated relapse rate (times per year) & $4.7 \pm 2.0(0.8-7.2)$ & $5.1 \pm 2.3(2.6-9.0)$ \\
Minimum dose of prednisolone & $0.7 \pm 0.3(0.5-1.2)$ & $0.8 \pm 0.3(0.4-1.2)$ \\
$\quad(\mathrm{mg} / \mathrm{kg}$ on alt. days) & & $133.9 \pm 17.9(106.7-159.0)$ \\
Estimated GFR $\left(\mathrm{mL} / \mathrm{min} .1 .73 \mathrm{~m}^{2}\right)$ & $143.7 \pm 34.7(107.5-215.0)$ & \\
\hline
\end{tabular}

${ }^{a}$ Values are expressed as the mean \pm S.D. (range).

${ }^{\mathrm{b}} P$-value $<0.01,{ }^{\mathrm{c}} P$-value $<0.05$.

CsA, cyclosporine A; $\mathrm{C}_{0}$ level, trough blood level of CsA; $\mathrm{C}_{2}$ level, blood level of CsA after 2 hours after its administration; SDD, single-daily dose administration; TDD, twice-daily dose administration. 
Table 2. Post treatment evaluation of patients administered CsA according to the SDD protocol or the TDD protocol ${ }^{\mathrm{a}}$.

\begin{tabular}{lcc}
\hline \multicolumn{1}{c}{ Variable } & $\operatorname{SDD}$ group $(n=10)$ & TDD group $(n=9)$ \\
\hline CsA treatment duration (months) & $26.7 \pm 9.9(13-39)$ & $34.9 \pm 17.2(13-68)$ \\
Calculated relapse rate (times per year) & $0.5 \pm 0.2(0-1.2)$ & $0.8 \pm 0.8(0-2.8)$ \\
Minimum dose of prednisolone (mg/kg on alt. days) & $0.1 \pm 0.1(0-0.2)$ & $0.2 \pm 0.2(0-0.5)$ \\
Estimated GFR (mL/min.1.73 $\left.\mathrm{m}^{2}\right)$ & $142.6 \pm 23.2(103.5-192.0)$ & $146.2 \pm 27.8(109.2-186.0)$ \\
Latest observation point from CsA (months) & $34.9 \pm 17.2(13-68)$ & $67.0 \pm 30.5^{\mathrm{b}}(25-111)$ \\
\hline
\end{tabular}

${ }^{a}$ Values are expressed as the mean \pm S.D. (range).

${ }^{\mathrm{b}} P$-value $<0.01$.

CsA, cyclosporine A; SDD, single-daily dose administration; TDD, twice-daily dose administration.

ment was significantly shorter in the SDD group, $30 \%(3 / 10)$ of patients in the SDD group and $33 \%$ (3/9) of those in the TDD group achieved long-sustained remission without medication. Seven $(70 \%)$ patients in the SDD group and 6 $(67 \%)$ in the TDD group experienced relapses, and one patient in the TDD group developed frequent relapses thereafter.

Except for one case in the TDD group, none of the renal biopsy specimens obtained after treatment showed any evidence of CsA nephrotoxicity. The patient in whom mild nephrotoxicity (a hyperplasia of the juxtaglomerular apparatus and a mild arteriolar hyalinosis which was confirmed by scheduled renal biopsy) was observed was a 15-year-old boy who had been treated with CsA according to the TDD protocol for 48 months. However, his estimated GFR remained normal throughout the clinical course, and CsA was successfully discontinued thereafter. No serious adverse effects, such as major or minor infections due to CsA treatment, liver dysfunction, hypertension or gingival hypertrophy were observed in any of these patients.

\section{Discussion}

It has been shown that long-term moderate to low-dose CsA according to the TDD protocol is effective and relatively safe for children with SDRNS (Hino et al. 1998; Inoue et al. 1999; El-Husseini et al. 2005). However, CsA nephrotoxicity remains a major problem (Hino et al. 1998; Inoue et al. 1999; Iijima et al. 2002). In this regard, it has been reported that young age at the start of CsA treatment, a high frequency of relapses during CsA treatment, CsA treatment for more than 2 years, and the duration of heavy proteinuria while on CsA treatment are significant risk factors for the development of CsA nephrotoxicity (Inoue et al. 1999; Iijima et al. 2002). In this context, Takeda et al. reported that once-daily administration of CsA prevented progression of chronic CsA nephrotoxicity, and that the administration of low doses of CsA following the SDD protocol could shorten the exposure to the drug (Takeda et al. 2007). Thus, the development of an optimal CsA treatment strategy for SDRNS, with the lowest possible dose of CsA was sought to minimize treatment toxicity, while maintaining its efficacy (Nakahata et al. 2005; Fujinaga et al. 2008).

In this paper, we retrospectively evaluated the useful- ness and safety of long-term CsA treatment using the SDD protocol versus the TDD protocol in children with SDRNS. Although the daily CsA dose and the $\mathrm{C}_{0}$ level of the drug were significantly lower in SDD patients than that in TDD patients, no significant differences were observed in terms of steroid-sparing effect, decrease in the calculated relapse rate following CsA treatment, and influence on the estimated GFR between the two groups. As a result, the long-term efficacy of CsA did not differ substantially between the two groups, although the observation period was relatively longer for TDD patients. Posttreatment renal biopsies also suggested the relative safety of CsA treatment administered in accordance with the SDD protocol (Tanaka et al. 2006a). We think that the $\mathrm{C}_{2}$ point blood level of CsA achieved with the SDD protocol accounted for an efficacy equal to that attained with the TDD protocol, while the low $\mathrm{C}_{0}$ blood level of the drug probably accounted for its safety, although this remains speculative (Nakahata et al. 2005; Takeda et al. 2007). We previously confirmed that the $C_{2}$ point blood level of CsA showed a reliable correlation with the $\mathrm{AUC}_{0-4}$ value of the drug in most patients with SDRNS (Nakahata et al. 2005; Tanaka et al. 2006b; Takeda et al. 2007). Although the most appropriate target $\mathrm{AUC}_{0-4}$ value of $\mathrm{CsA}$ for the treatment of SDRNS remains speculative, it has been reported that around $2000 \mathrm{ng} \times$ hour/ml might be appropriate for renal transplant patients in the maintenance phase (Uchida et al. 2004). Indeed, we have confirmed most SDRNS patients, not all the patients, respond well to the $\mathrm{SDD}$ protocol in this $\mathrm{AUC}_{0-4}$ setting of the drug. Thus, we also think that supposed adequate target $\mathrm{AUC}_{0-4}$ value of CsA for the treatment of SDRNS is around $2000 \mathrm{ng} \times$ hour/ ml (Tanaka et al. 2006b).

Fujinaga et al. (2008) recently reported they had obtained limited efficacy of the SDD protocol in CsAdependent patients. We also experienced a patient with CsA-dependent, long-standing SDRNS in whom the TDD protocol was needed to achieve clinical remission while the SDD protocol proved ineffective despite the sufficient $\mathrm{C}_{2}$ point blood level of the drug (Tanaka et al. 2006b). Thus, in a proportion of patients with SDRNS, it may be necessary to inhibit the calcineurin expressed by lymphocytes more than once a day for a successful treatment. Further studies are needed to resolve this issue. 
Despite a retrospective study that involved a small number of patients and that insufficient data were obtained from posttreatment renal biopsies, we suggest that CsA treatment using the SDD protocol is at least as effective as treatment with the conventional TDD protocol, and it is attractive in terms of substantial savings in costs for children with SDRNS. Moreover, this protocol may improve treatment compliance. We, therefore, suggest that CsA administered once daily may serve as an initial alternative therapy to PDN alone in selected patients with SDRNS. However, it is difficult to arrive at a definitive conclusion based on the results of this study. Further prospective studies involving a larger number of patients are needed to confirm our preliminary results.

\section{References}

El-Husseini, A., El-Basuony, F., Mahmoud, I., Sheashaa, H., Sabry, A., Hassan, R., Taha, N., Hassan, N., Sayed-Ahamad, N. \& Sobh, M. (2005) Long-term effects of cyclosporine in children with idiopathic nephrotic syndrome: a single-centre experience. Nephrol. Dial. Transplant., 20, 2433-2438.

Fujinaga, S., Ohtomo, Y., Someya, T., Shimizu, T., Yamashiro, Y. \& Kaneko, K. (2008) Is single-daily low-dose cyclosporine therapy really effective in children with idiopathic frequent-relapsing nephrotic syndrome? Clin. Nephrol., 69, 84-89.

Hino, S., Takemura, T., Okada, M., Murakami, K., Yagi, K., Fukushima, K. \& Yoshioka, K. (1998) Follow-up study of children with nephrotic syndrome treated with a long-term moderate dose of cyclosporine. Am. J. Kidney Dis., 31, 932-939.

Iijima, K., Hamahira, K., Tanaka, R., Kobayashi, A., Nozu, K., Nakamura, H. \& Yoshikawa, N. (2002) Risk factors for cyclosporine-induced tubulointerstitial lesions in children with minimal change nephrotic syndrome. Kidney Int., 61, 1801-1805.

Inoue, Y., Iijima, K., Nakamura, H. \& Yoshikawa, N. (1999) Twoyear cyclosporine treatment in children with steroid-dependent nephrotic syndrome. Pediatr. Nephrol., 13, 33-38.

Kano, K., Kyo, K., Yamada, Y., Ito, S., Ando, T. \& Arisaka, O. (1999) Comparison between pre- and posttreatment clinical and renal biopsies in children receiving low dose cyclospo-
rine-A for 2 years for steroid-dependent nephrotic syndrome. Clin. Nephrol., 52, 19-24.

Nakahata, T., Tanaka, H., Tsugawa, K., Kudo, M., Suzuki, K., Ito, E. \& Waga, S. (2005) $\mathrm{C}_{1}-\mathrm{C}_{2}$ point monitoring of low-dose cyclosporine A given as a single daily dose in children with steroiddependent relapsing nephrotic syndrome. Clin. Nephrol., 64, 258-263.

Rasche, F.M., Keller, F., Kunze, G., Boesler, B. \& Czock, D. (2007) Single daily dose of cyclosporine in patients with primary glomerulonephritis and nephrotic syndrome. Clin. Nephrol., 67, 285-292.

Ruth, E.M., Kemper, M.J., Leumann, E.P., Laube, G.F. \& Neuhaus, T.J. (2005) Children with steroid-sensitive nephrotic syndrome come of age: long-term outcome. J. Pediatr., 147, 202-207.

Schwartz, G.J. (1992) Does kL/Pcr estimate GFR, or does GFR determine k? Pediatr. Nephrol., 6, 512-515.

Takeda, A., Horike, K., Onoda, H., Ohtsuka, Y., Yoshida, A., Uchida, K. \& Morozumi, K. (2007) Benefits of cyclosporine absorption profiling in nephrotic syndrome: Preprandial oncedaily administration of cyclosporine microemulsion improves slow absorption and can standardize the absorption profile. Nephrology (Carlton), 12, 197-204.

Tanaka, H., Nakahata, T. \& Ito, E. (2004) Single-dose daily administration of cyclosporine A for relapsing nephrotic syndrome. Pediatr. Nephrol., 19, 1055-1058.

Tanaka, H., Tsugawa, K., Suzuki, K. \& Ito, E. (2006a) Renal biopsy findings in children receiving long-term treatment with cyclosporine A given as a single daily dose. Tohoku J. Exp. Med., 209, 191-196.

Tanaka, H., Tsugawa, K., Tsuruga, K., Shimada, J., Suzuki, K. \& Ito, E. (2006b) Single-dose daily treatment with cyclosporin A for relapsing nephrotic syndrome: report of a case showing poor response. Clin. Nephrol., 66, 219-220.

The International Study of Kidney Disease in Children (1981) The primary nephrotic syndrome in children: identification of patients with minimal change nephrotic syndrome from initial response to prednisone: a report of the International Study of Kidney Disease in Children. J. Pediatr., 98, 561-564.

Uchida, K., Tominaga, Y., Haba, T., Katayama, A., Matsuoka, S., Goto, N., Ueki, T., Kimata, T., Takeda, A., Morozumi, K., Takagi, H. \& Nakao, A. (2004) Clinical success of Neoral absorption profile. Transplant. Proc., 36 (Suppl 2S), 461S464S. 